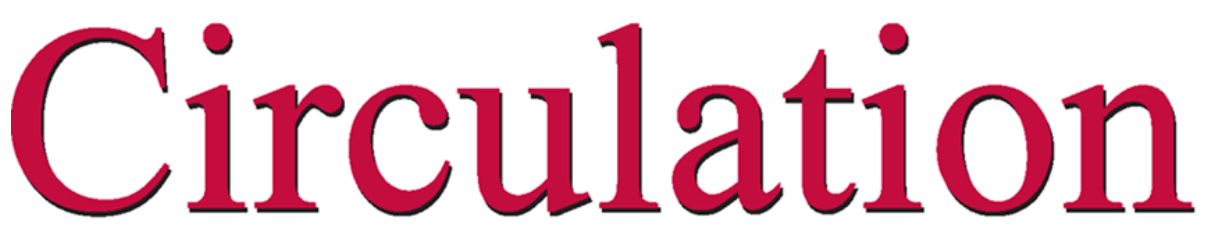

JOURNAL OF THE AMERICAN HEART ASSOCIATION
American Heart Association

Learn and Live

\title{
Magnetic Resonance Angiography of a Pulmonary Artery Stenosis Late After Cardiac Surgery
}

Robert J. M. van Geuns, Matthijs Oudkerk, Pim J. de Feyter and Silja E. Spitaels Circulation 2000;102;71-72

Circulation is published by the American Heart Association. 7272 Greenville Avenue, Dallas, TX 72514

Copyright $@ 2000$ American Heart Association. All rights reserved. Print ISSN: 0009-7322. Online ISSN: $1524-4539$

The online version of this article, along with updated information and services, is located on the World Wide Web at:

http://circ.ahajournals.org/cgi/content/full/102/11/e71

Subscriptions: Information about subscribing to Circulation is online at http://circ.ahajournals.org/subsriptions/

Permissions: Permissions \& Rights Desk, Lippincott Williams \& Wilkins, 351 West Camden Street, Baltimore, MD 21202-2436. Phone 410-5280-4050. Fax: 410-528-8550. Email:

journalpermissions@1ww.com

Reprints: Information about reprints can be found online at http://www.lww.com/static/html/reprints.html 


\title{
Magnetic Resonance Angiography of a Pulmonary Artery Stenosis Late After Cardiac Surgery
}

\author{
Robert J.M. van Geuns, MD; Matthijs Oudkerk, MD, PhD; \\ Pim J. de Feyter, MD, PhD; Silja E. Spitaels, MD, PhD
}

\begin{abstract}
A
19-year-old man with known dextrocardia, situs inversus, and complete surgical correction of a double-outlet right ventricle was seen in the outpatient clinic for follow-up after total correction, including the implantation of a pulmonary homograft. During echocardiography, a dilated right atrium and right ventricle were noted. Increased right ventricular pressure (50 $\mathrm{mm} \mathrm{Hg}$; tricuspid regurgitation, $3.5 \mathrm{~m} / \mathrm{s}$ ) could only partially be explained by pulmonary valve stenosis. The pulmonary artery branches could not be visualized echocardiographically. Magnetic resonance angiography was performed using the breath-hold contrast-enhanced 3D gradient echo sequence described by Prince et al. ${ }^{1}$ The imaging time was 24 seconds and the resolution was $1.0 \times 2.6 \times 1.3 \mathrm{~mm}$. After the acquisition, the datasets were transferred to a dedicated graphic workstation (Indigo2, Silicon Graphics) for 3D evaluation with a volume-rendering technique ${ }^{2,3}$ using commercially available software (VoxelView, Vital Images). Three-dimensional representation with volume rendering showed the situs inversus very clearly (Figure 1). The pulmonary homograft is located on the right side of the patient, with the ascending aorta on the left and
\end{abstract}

descending aorta to the right of the spine. The branch vessels are reversed, with a left brachiocephalic artery as the first arch branch.

To visualize the pulmonary artery branches, the heart and aorta were subtracted from the source images (Figure 2). Both the pulmonary arteries and veins are filled with contrast. The right pulmonary artery showed an important stenosis at the anastomosis from the pulmonary homograft. Figure 3 is a detailed view of the origin of the right pulmonary artery.

The diagnosis was confirmed during reoperation, which consisted of implanting a new pulmonary homograft and reconstructing the right pulmonary artery.

\section{References}

1. Prince MR, Narasimham DL, Stanley JC, et al. Breath-hold gadoliniumenhanced MR angiography of the abdominal aorta and its major branches. Radiology. 1995; 197:785-792.

2. Fishman EK, Magid D, Ney DR, et al. Three-dimensional imaging. Radiology. 1991;181:321-337.

3. Johnson PT, Heath DG, Kuszyk BS, et al. CT angiography with volume rendering: advantages and applications in splanchnic vascular imaging. Radiology. 1996;200:564-568

From the Department of Cardiology, Thoraxcenter (R.J.M.v.G., P.J.d.F., S.E.S.) and the Department of Radiology, Dr Daniel den Hoedkliniek, University Hospital Rotterdam (M.O.), Rotterdam, The Netherlands.

Correspondence to Robert J.M. van Geuns, MD, Department of Cardiology, Thoraxcenter, Bd 406, University Hospital Rotterdam, PO Box 2040,3000

CA Rotterdam, The Netherlands. E-mail vangeuns@ card.azr.nl

A movie version of Figure 2 (showing 3D rotation) can be found at www.circulationaha.org

The editor of Images in Cardiovascular Medicine is Hugh A. McAllister, Jr, MD, Chief, Department of Pathology, St Luke's Episcopal Hospital and

Texas Heart Institute, and Clinical Professor of Pathology, University of Texas Medical School and Baylor College of Medicine.

Circulation encourages readers to submit cardiovascular images to the Circulation Editorial Office, St Luke's Episcopal Hospital/Texas Heart Institute,

6720 Bertner Ave, MC1-267, Houston, TX 77030.

(Circulation. 2000;102:e71-e72.)

(C) 2000 American Heart Association, Inc.

Circulation is available at http://www.circulationaha.org 


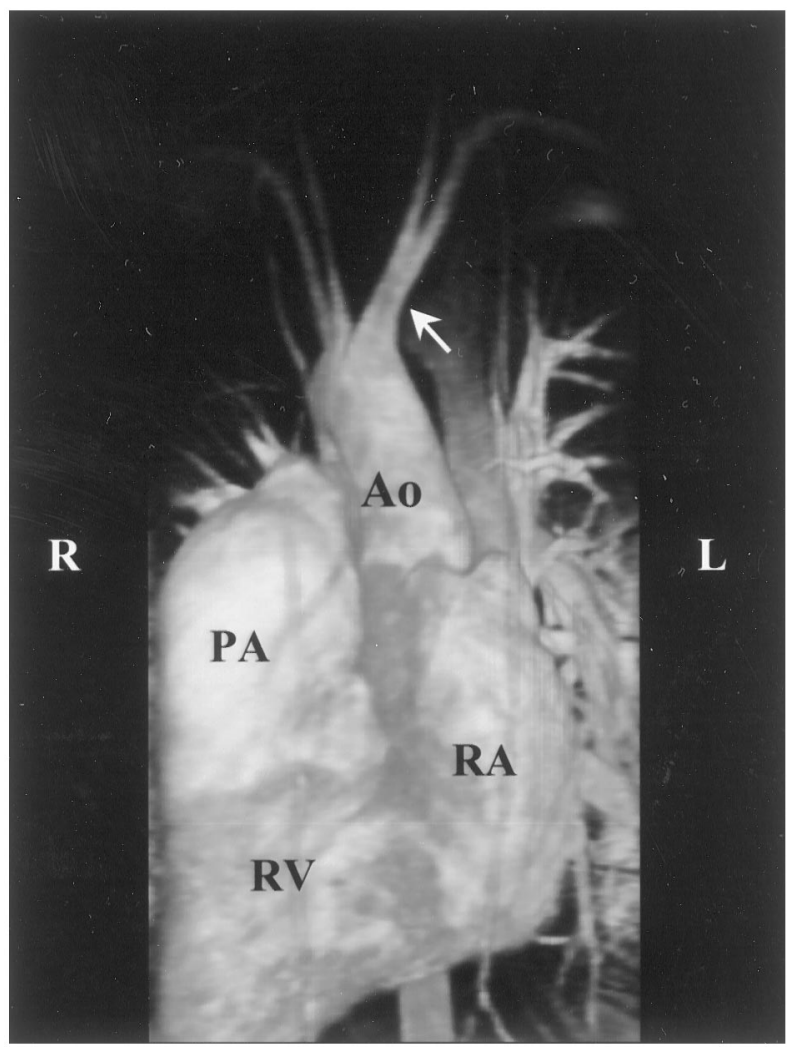

Figure 1. Breath-hold contrast-enhanced magnetic resonance angiography of a patient with situs inversus. Ao indicates aorta; PA, pulmonary artery; RV, right ventricle; RA, right atrium; $R$, right side of patient; and $\mathrm{L}$, left side of patient. Arrow indicates left brachiocephalic artery.

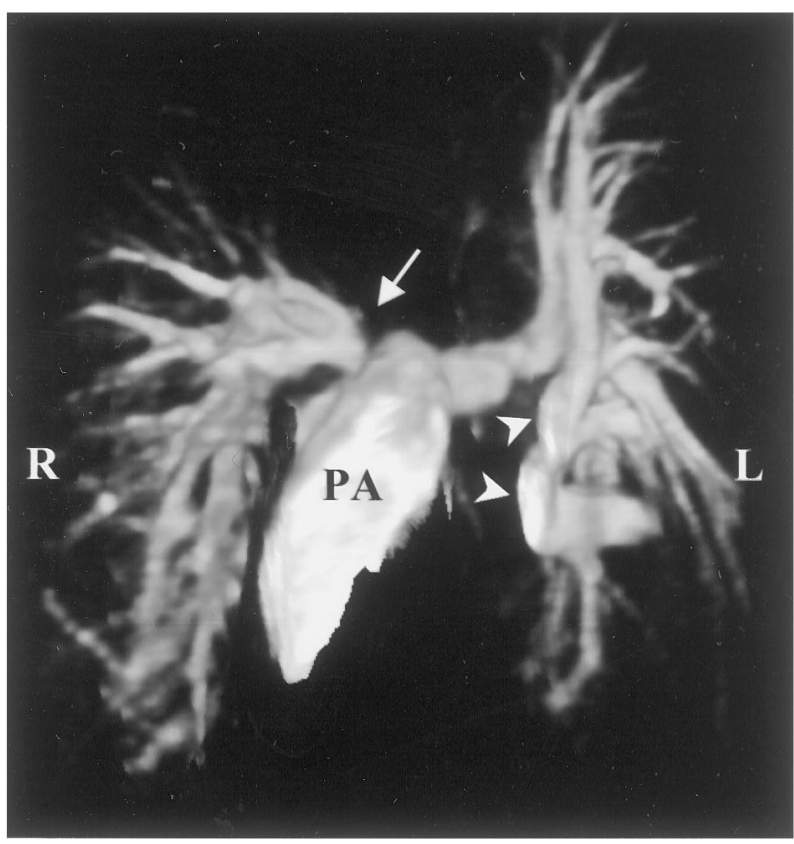

Figure 2. Visualization of the pulmonary artery (PA) after removal of the heart and aorta from the dataset. The pulmonary veins are also visualized (arrowheads). The right pulmonary artery shows an important stenosis at the origin (straight arrow). $R$ indicates right side of patient; $L$, left. The $3 D$ rotation of this image can be found at www.circulationaha.org

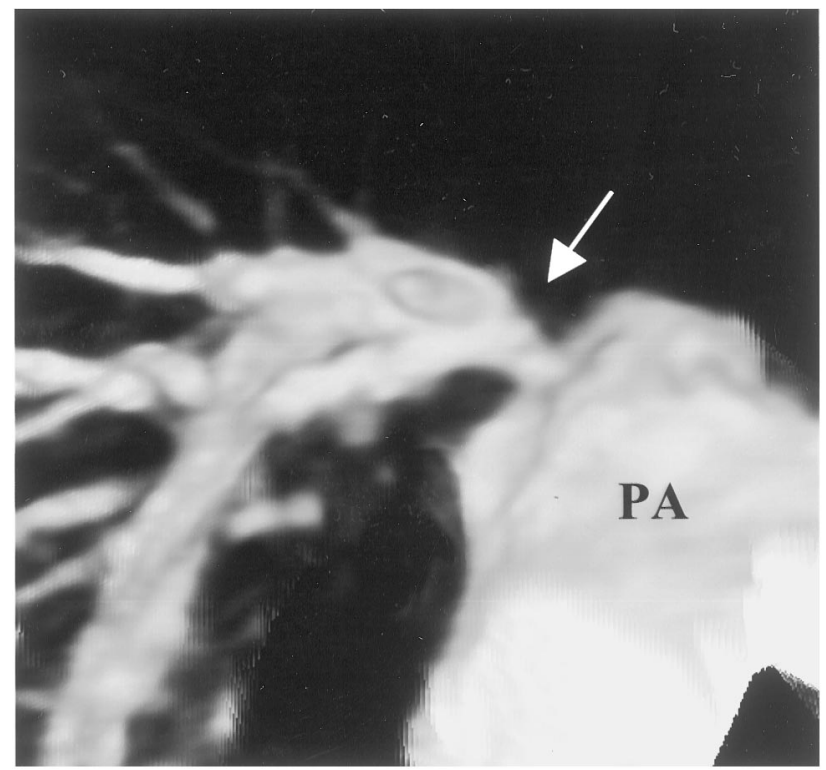

Figure 3. Detailed view of the common pulmonary artery (PA) and proximal right pulmonary artery showing a stenosis at the origin (straight arrow). 